\title{
Validation of Health Extension Workers Job Motivation Scale in Gamo-Gofa Zone, Southern Ethiopia: A Cross-Sectional Study
}

\author{
Shikur Mohammed, ${ }^{1}$ Marelign Tilahun, ${ }^{1}$ Mesfin Kote, ${ }^{1}$ \\ Mohamedaman Mama, ${ }^{1}$ and Dessalegn Tamiru ${ }^{2}$ \\ ${ }^{1}$ Department of Public Health, Arba Minch University, P.O. Box 21, Arba Minch, Ethiopia
}

${ }^{2}$ Department of Population and Family Health, Jimma University, Jimma, Ethiopia

Correspondence should be addressed to Shikur Mohammed; m_shikur@yahoo.com

Received 18 October 2014; Revised 31 January 2015; Accepted 3 February 2015

Academic Editor: Aldo Rosano

Copyright (C) 2015 Shikur Mohammed et al. This is an open access article distributed under the Creative Commons Attribution License, which permits unrestricted use, distribution, and reproduction in any medium, provided the original work is properly cited.

\begin{abstract}
Introduction. Well-trained and highly motivated community health workers are critical for delivery of community-based health care services. Understanding what motivates especially community health care providers for better community health requires the use of psychometrically reliable and valid scale. This study was conducted to validate job motivation scale in Gamo Gofa Zone, Southern Ethiopia. Methods. A cross-sectional study was conducted in 150 health care posts in Gamo Gofa Zone, from February 01, 2013, to March 01, 2013. A total of 301 participants responded to questionnaires asking about sociodemographic characteristics and job motivation. Exploratory factor analysis with principal component extraction and varimax with Kaiser Normalization rotation were employed to develop scales for job motivation. Eigenvalues greater than 1 were used as criterion of extraction. Items with item factor loadings less than 0.4 and double loaded items were dropped. Alpha and exploratory factor analyses were examined to test reliability and validity of the scale. Results. During exploratory factor analysis eight factors emerged from the three dimensions of job motivation scale, namely, educational career, workload, financial incentive, supervisor encouragement, community recognition, access to infrastructure, living condition, and better achievement in work. The factor loadings of the items in each dimension ranged from 0.58 to 0.83 . Crobach's alpha of the scales ranged from 0.79 to 0.90 . To check validities of the scales developed in this study, the previous studies conducted to develop job motivation scale were used. Conclusion. Although the present scale has the potential to measure the job motivation of health extension workers and it is low in cost and easy to administer and analyze, it should be field-tested at different settings.
\end{abstract}

\section{Introduction}

Recognizing the huge gap between the need and health care services available, Ethiopia launched new health extension program (HEP) to provide health care services in accessible and equitable manner to all segments of the population with special attention to mothers and children. Moreover, the majority of the health problems in Ethiopia are due to infectious diseases, which are better managed by an approach that focuses on preventive and promotive health services $[1,2]$.

As a preventive health program, the HEP promotes four areas of care: disease prevention and control, family health, hygiene and environmental sanitation, and health education and communication [1].

Health extension workers (HEWs) are the cadre for the implementation of health extension program. All HEWs are women at least 18 years of age with a minimum of 10th grade education recruited from the communities in which they will work, who are trained to implement health extension packages of 16 health care activities at the kebele (village) level and must complete a one-year course of training. Upon completion of training they are assigned in pairs in kebele where they were recruited first and work directly with individual families to serve 500 households. They are expected to spend 75 percent of their time visiting families in their 
homes and performing outreach activities in the community. The remaining 25 percent of their time is expected to be spent providing services at the health posts, like immunizations, family planning services, and others [3].

To address community demands for basic curative care, HEWs are also trained to provide first aid, treat malaria, dysentery, and intestinal parasites, and refer cases to the nearest health center when more advance care is needed $[1,3]$.

The health care provider motivation has often been identified as a central problem in health service delivery and quality $[4,5]$. Low motivation leads to insufficient translation of knowledge, underutilization of available resources, and weak health system performance. Poor worker motivation can manifest as tiredness, absenteeism, poor process quality, turnover rate, high vacancy rates, and indifferent performance [5].

Study conducted in Ethiopia revealed that poor transportation and communication systems, inconsistent availability of minimum standard of equipment and furniture, salary level which seems inadequate, and not being appreciated by the colleagues demotivated health extension workers [6]. However, this has been conducted where the career structure, upgrading, promotion, and rewards for health extension workers had not been formally established.

The successful delivery of lifesaving programs depends on the motivation and effective job performance of health workers [4]. Therefore, this study was done to validate health extension workers job motivation scale in Gamo-Gofa Zone.

\section{Methods}

2.1. Study Settings. The study was conducted among health extension workers in Gamo-Gofa Zone, Southern Ethiopia. The total area of Gamo-Gofa Zone is about 12,004.26 sq/km. The zone has 17 districts ( 15 rural districts and 2 urban district administrations) and 482 kebeles (448 rural kebeles and 34 urban kebeles) with total population of $1,837,896$ [7, 8].

The zone has 3 hospitals, 66 health centers, 471 community health posts, and 125 private clinics and the health service coverage at health center and health post level is $100 \%$. There were 831 health extension workers in the zone where 763 were rural health extension workers [7].

2.2. Study Design and Population. A cross-sectional study design was used. All health extension workers who were working in Gamo-Gofa Zone were the source population; and all health extension workers who were working in selected districts of the zone were the study populations.

2.3. Sample Size and Sampling Procedure. The sample size was determined using single population proportion formula based on $31 \%$ proportion [9], marginal error of $5 \%(d=0.05)$ and standard score corresponding to $95 \%$ confidence $\left(Z_{\alpha / 2}=\right.$ 1.96) and design effect of 1.5. By applying the correct formula the final sample size was found to be 295 .

In Gamo-Gofa Zone there are 15 rural districts of which $5(30 \%)$ rural districts were selected using cluster sampling technique. Since the sampling technique was cluster sampling technique, all HEWs within the selected districts were included in the study. On average there were 30 kebeles in each district and 2 health extension workers in each kebele. So the required sample size was attained from the selected districts. List of HEWs in the selected districts was obtained from the respective district health offices.

2.4. Instruments and Measures. The questionnaires were developed in English after reviewing different literatures. The questionnaire contained sociodemographic variables (age, year of service, marital status, religion, monthly income, educational status, ethnicity, and additional source of income) and items (achievement in work, satisfaction with the work done, working hard towards quality service, interest to provide community services, satisfaction on monthly salary, satisfaction on field allowance, satisfaction on housing benefits, supervisor encouragement in decision making and working hard, supportive feedback, opportunity for upgrade/trainings, altruism, self-efficacy, community perception, relationship with local community, families' area of residence, access to transportation, water sources and market place, and convenient roads to move in the community) to measure work motivation $[10,11]$.

Amharic translated self-administered questionnaires were used to collect the data. Each question explored their level of motivation on a Likert scale of 1 (strongly disagree) to 5 (strongly agree). The construct of the questions was balanced with both positive and negative directions to prevent similar responses. The questionnaires were then pretested on the health extension workers in the health posts found in Arba Minch town (not included in the study), making up $5 \%$ of the study population, before the actual data collection began. Finally the Amharic questionnaires were translated back into English to ensure semantic equivalence.

Factor analysis with principal component extraction and varimax Kaiser Normalization rotation methods were employed to develop the job motivation scale. To determine factors "eigenvalue" was used and factors with values greater than 1.0 were kept and the rest discarded. Accordingly, eight factors emerged. After the appropriate number of factors had been determined, a factor correlation matrix was done to identify the relationship between the items and the factors. A value of 0.40 was taken as the lower cut-off point for factor loading. When naming the factors, items that have higher factor loadings were taken as a base. The reliability of factors was checked against Cronbach's alpha greater than 0.7.

2.5. Data Processing and Analysis. Data were checked for completeness and were entered into Epi-info and then the data were exported to SPSS software (version 16.0; SPSS Inc., Chicago, IL) for analysis. The data were explored using descriptive analyses to clean data-entry errors. Factor analysis was then conducted to create scales for job motivation. Assumptions of factor analysis, including sampling adequacy and multicollinearity, were checked. Alpha and exploratory factor analyses were examined to test reliability and content validity of the scale. 
TABLE 1: The sociodemographic characteristics of health extension workers in Gamo-Gofa Zone, Southern Ethiopia, 2013.

\begin{tabular}{|c|c|c|}
\hline Variables & Frequency $(n=301)$ & Percent (\%) \\
\hline \multicolumn{3}{|l|}{ Marital status } \\
\hline Married & 196 & 65.1 \\
\hline Not married & 105 & 34.9 \\
\hline \multicolumn{3}{|l|}{ Religion } \\
\hline Orthodox Christian & 106 & 35.2 \\
\hline Protestant Christian & 185 & 61.5 \\
\hline Muslim & 10 & 3.3 \\
\hline \multicolumn{3}{|c|}{ HEWs in the current health post } \\
\hline One & 32 & 10.6 \\
\hline Two & 237 & 78.7 \\
\hline Three & 18 & 5.9 \\
\hline Four & 14 & 4.8 \\
\hline \multicolumn{3}{|c|}{ Additional source of income ${ }^{*}$} \\
\hline Yes & 210 & 69.8 \\
\hline No & 91 & 30.2 \\
\hline \multicolumn{3}{|l|}{ Current educational level } \\
\hline Attended 10th grade & 216 & 71.8 \\
\hline Above 10th grade & 85 & 28.2 \\
\hline Service year & \multicolumn{2}{|c|}{ Average $5.1(\mathrm{SD} \pm 2.1)$ years } \\
\hline Age & \multicolumn{2}{|c|}{ Average $26.2(\mathrm{SD} \pm 3.3)$ years } \\
\hline
\end{tabular}

2.6. Ethical Consideration. The research proposal was approved by the ethical review committees of Arba Minch University, College of Medicine and Health Sciences. Permission letter was obtained from the Gamo-Gofa Zone health department and the respective district health offices. Oral informed consent was obtained from the study participants before the commencement of data collection. The right of study participants to refuse participation or withdraw from the study at any point was respected. All accessed data were kept confidential and only accessed by the study teams. Data were not shared with anybody in a way respondents' individual identity was identified.

\section{Results}

3.1. Characteristics of Respondents. A total of $301 \mathrm{HEW}$ s were included in this study although the proposed sample size was 295. In this study complete response was obtained from all $(100 \%)$ respondents. The mean age of the respondents was $26.2(\mathrm{SD} \pm 3.3)$. The majority of study participants 196 (65.1\%) were married and $216(71.8 \%)$ attended 10th grade. About $30 \%$ of the study participants did not have any other personal sources of earning. The mean service year of study participants was $5.1(\mathrm{SD} \pm 2.1)$ (Table 1$)$.

3.2. Scale Development. Job motivation contained three dimensions: institutional dimension, societal dimension, and individual work performance dimension. During exploratory factor analysis, four factors emerged from the institutional dimension. In this dimension, educational career, workload, financial incentives, and supervisor encouragement explained $26.3 \%, 11.4 \%, 18.7 \%$, and $24.6 \%$ of the total variance, respectively. The numbers of the items were four for educational career, two for workload, four for financial incentives, and four for the supervisor encouragement. In general, factor loadings of the institutional dimensions items on their respective factors ranged from 0.61 to 0.83 (Table 2). Cronbach's alphas of the four scales were $0.91,0.88,0.85$, and 0.80 , respectively (data not presented).

There were three factors that emerged from the societal dimension, which accounted for $33.5 \%$ (community recognition), 31.3\% (infrastructures accesses), and 22.3\% (living condition) of the total variance, respectively. Community recognition had three items. Infrastructures access had five items. Living condition had four items. Generally, the factor loadings of the societal dimension items ranged from 0.66 to 0.77 (Table 3). Cronbach's alphas of the three scales were 0.86 , 0.81 , and 0.79 , respectively (data not presented).

One significant factor emerged from the work performance dimension, representing $61.2 \%$ of the total variance. This factor had four components, with factor loadings of the four items ranging from 0.59 to 0.80 (Table 4). Cronbach's alpha of the scale was 0.89 (data not presented).

\section{Discussion}

In this study job motivation contained three dimensions: institutional, societal, and individual work performance. This was in line with studies conducted in developing countries and Kenya where worker motivation was malleable and was affected by changes in the individual worker, work conditions, and broader social environment $[12,13]$.

In this study eight factors emerged from job motivation dimensions of health extension workers, namely, live conditions, access to infrastructure, community recognition, financial incentive, educational career, workload, better achievement in work, and supervisor encouragement.

Studies revealed that access to appropriate infrastructures and living conditions can significantly improve health workers morale [5].

In this study community recognition was found to be one of health extension workers job motivation scales. Studies conducted in Vietnam, Kenya, and developing countries showed that the value which the community gives to community health workers was found as category of job motivation scale $[9,12,13]$. The possible explanation could be high participation of the community in the identification of their common health problems and implementation of healthsector activities leads to greater acceptance and use of services, which may also make health extension workers think as they are getting better recognition from the community and develop sense of self-altruism. Experience elsewhere shows that the greater the participation of the community, the greater the acceptance and use of services and the lesser the demand for expensive curative services [14].

In the current study financial incentive was found to be one emerging factor of health extension workers job 
TABLE 2: Factor loadings of the items used to measure the institutional support dimensions of job motivation by health extension workers, Southern Ethiopia, 2013.

\begin{tabular}{|c|c|c|c|c|}
\hline Items & Education career & Workload & Financial incentive & Supervisor encourage \\
\hline Opportunity for upgrade and trainings & 0.72 & & & \\
\hline Opportunity of refresher trainings & 0.69 & & & \\
\hline No skill gap & 0.62 & & & \\
\hline Ability to deal with outbreaks & 0.65 & & & \\
\hline No shortage of materials and equipment & & 0.72 & & \\
\hline Duties assigned are not too much & & 0.76 & & \\
\hline Satisfaction on monthly salary & & & 0.83 & \\
\hline Satisfied on field allowance & & & 0.68 & \\
\hline Satisfied on hardship allowance & & & 0.65 & \\
\hline Satisfied on housing benefits & & & 0.71 & \\
\hline Supervisor encourages in decision & & & & 0.66 \\
\hline Supervisor encourages to work hard & & & & 0.68 \\
\hline Supervisor gives supportive feedback & & & & 0.61 \\
\hline Supervisor makes HEWs feel valued & & & & 0.62 \\
\hline
\end{tabular}

TABLE 3: Factor loadings of the items used to measure the societal support dimensions of job motivation by health extension workers, Southern Ethiopia, 2013.

\begin{tabular}{|c|c|c|c|}
\hline Items & Community recognition & Infrastructures access & Living condition \\
\hline Good relationship with local community & 0.67 & & \\
\hline The community has good perception for the HP & 0.77 & & \\
\hline All people in the village use the HEP services & 0.66 & & \\
\hline Accessible schools for children & & 0.76 & \\
\hline Convenient roads to move in the community & & 0.70 & \\
\hline No transportation problem & & 0.69 & \\
\hline Families are living in nearest place & & 0.74 & \\
\hline Water sources are in nearest place & & 0.72 & \\
\hline Living within $1 \mathrm{~km}$ far from $\mathrm{HP}$ & & & 0.75 \\
\hline Living within $1 \mathrm{~km}$ far from water source & & & 0.70 \\
\hline Living within $1 \mathrm{~km}$ far from market place & & & 0.73 \\
\hline Living in compound of HP & & & 0.72 \\
\hline
\end{tabular}

TABLE 4: Factor loadings of the items used to measure the work performance dimension of job motivation by health extension workers, Southern Ethiopia, 2013.

\begin{tabular}{lc}
\hline Items & Better achievement \\
\hline Achieve more in my work & 0.80 \\
Satisfied with the work done & 0.71 \\
Working hard for provision of quality service & 0.64 \\
Frequent visit to provide community services & 0.59 \\
\hline
\end{tabular}

motivation scale. It is clear that financial incentives are highly influential in health worker motivation; furthermore financial incentives are factors that can significantly improve morale [10].

Again educational career was found as category for health extension workers job motivation scale. Study conducted in Vietnam showed that training was a motivating factor for workers [9]. The possible explanation could be that training enables health extension workers to take on more demanding duties and to achieve professional advancement as well as allow them to cope better with the requirements of their job. This indicates that refresher courses or trainings to reinforce current knowledge of the health extension workers are mandatory.

This study also showed that workload and better work achievement are the other categories of health extension workers job motivation scale. The study conducted in developing countries showed that the amount of work was found to be one category for job motivation scale [13]. Health planners or managers should understand how much workload affects the coverage, quality, and equity of health services provided by HEWs to their communities as heavy/overburden workloads have a tendency to discourage HEWs in quality equitable service provision.

\section{Conclusion}

This job motivation scale can be used or adapted to measure job motivation of community health workers and other 
professionals who are working in different settings. Further implementation research is needed in differing setting to further refine the scale.

\section{Conflict of Interests}

The authors declare that they have no competing interests.

\section{Authors' Contribution}

Shikur Mohammed (the corresponding author) designed and supervised the study, ensured the quality of the data, and worked on the analysis and interpretation of the data. Mesfin Kote, Marelign Tilahun, Dessalegn Tamiru, and Mohamedaman Mama ensured the quality of data and reviewed the paper for publication. All authors read and approved the final paper.

\section{Acknowledgments}

The authors would like to express their sincere gratitude to the Arba Minch University for funding the research project. They also acknowledge the study participants for their diligence and dedication in collecting and inputting the data.

\section{References}

[1] Ethiopian Federal Ministry of Health, The Accelerated Coverage of Primary Health Care in Ethiopia: 2005-2009, Ethiopian Federal Ministry of Health, Addis Ababa, Ethiopia, 2005.

[2] The Ethiopian Federal Minstry of Health, Implementation Guidelines of Health Extension Program, The Ethiopian Federal Minstry of Health, Addis Ababa, Ethiopia, 2008.

[3] Central Statistical Agency, Summary of Statistical Report of the 2007 Population and Housing Census, Central Statistical Agency, Addis Ababa, Ethiopia, 2008.

[4] World Health Organization, Training Manual on Management of Human Resources for Health. Section I, Part A, World Health Organization, Geneva, Switzerland, 1993.

[5] I. Mathauer and I. Imhoff, "Health worker motivation in Africa: the role of non-financial incentives and human resource management tools," Human Resources for Health, vol. 4, article 24, 2006.

[6] T. Awash, K. Yayehyirad, A. G. Yohannes et al., "Study of the working conditions of health extension workers in Ethiopia," Ethiopian Journal of Health Development, vol. 21, no. 3, pp. 246259, 2007.

[7] Central Statistical Authority [Ethiopia] and ORC Macro, Ethiopia Demographic and Health Survey 2011, Central Statistical Authority, Addis Ababa, Ethiopia; ORC Macro, Calverton, Md, USA, 2011.

[8] Central Statistical Agency, Summary of Statistical Report of 2007; Population and Housing Census, Central Statistical Agency, Addis Ababa, Ethiopia, 2013.

[9] M. Dieleman, P. V. Cuong, L. V. Anh, and T. Martineau, "Identifying factors for job motivation of rural health workers in North Viet Nam," Human Resources for Health, vol. 1, article $10,2003$.

[10] L. M. Franco, S. Bennett, and R. Kanfer, "Health sector reform and public sector health worker motivation: a conceptual framework," Social Science \& Medicine, vol. 54, no. 8, pp. 1255$1266,2002$.

[11] J. Martinez, Assessing Quality, Outcome and Performance Management, World Health Organization, Geneva, Switzerland, 2001.

[12] R. Kanfer, Measuring Health Worker Motivation in Developing Countries. Major Applied Research 5, ABT Associates, Bethesda, Md, USA, 1999.

[13] L. M. Franco, S. Bennett, and R. Kanfer, "Health sector reform and public sector health worker motivation: a conceptual framework," Social Science and Medicine, vol. 54, no. 8, pp. 12551266, 2002.

[14] Better Health in Africa: Experience and Lessons Learned, WB, 1994. 


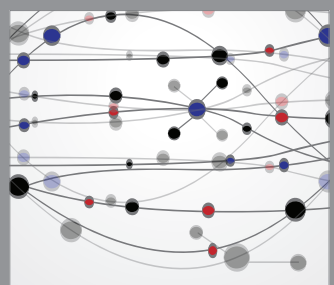

The Scientific World Journal
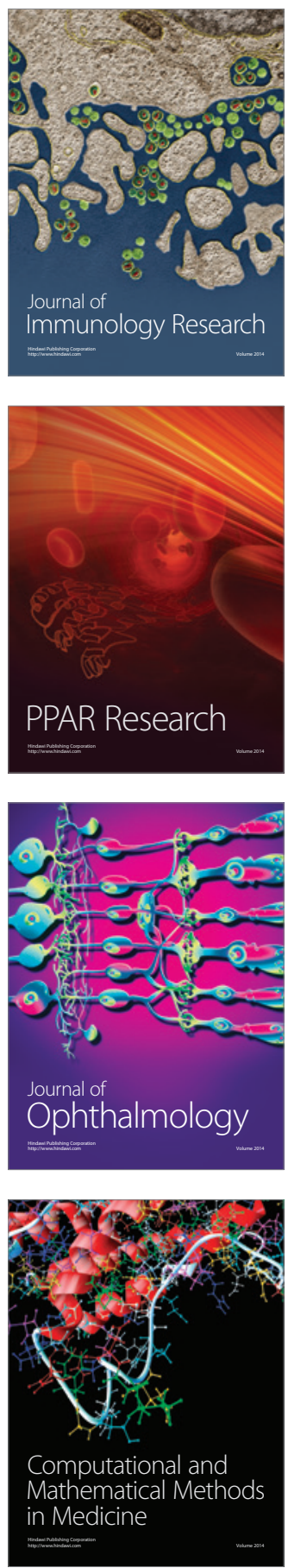

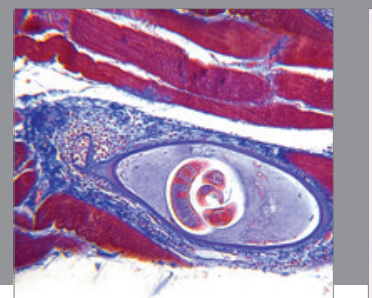

Gastroenterology

Research and Practice
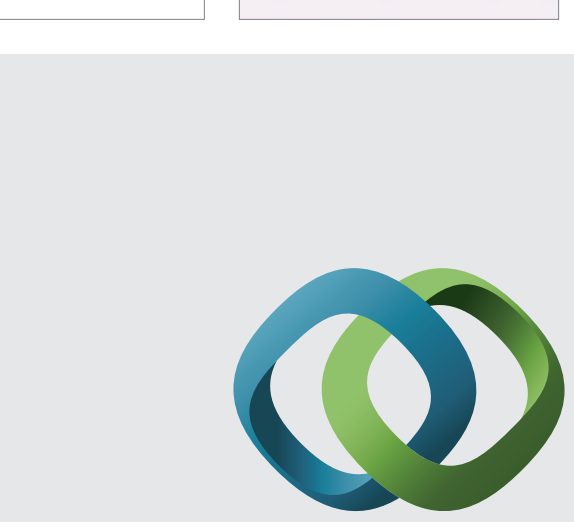

\section{Hindawi}

Submit your manuscripts at

http://www.hindawi.com
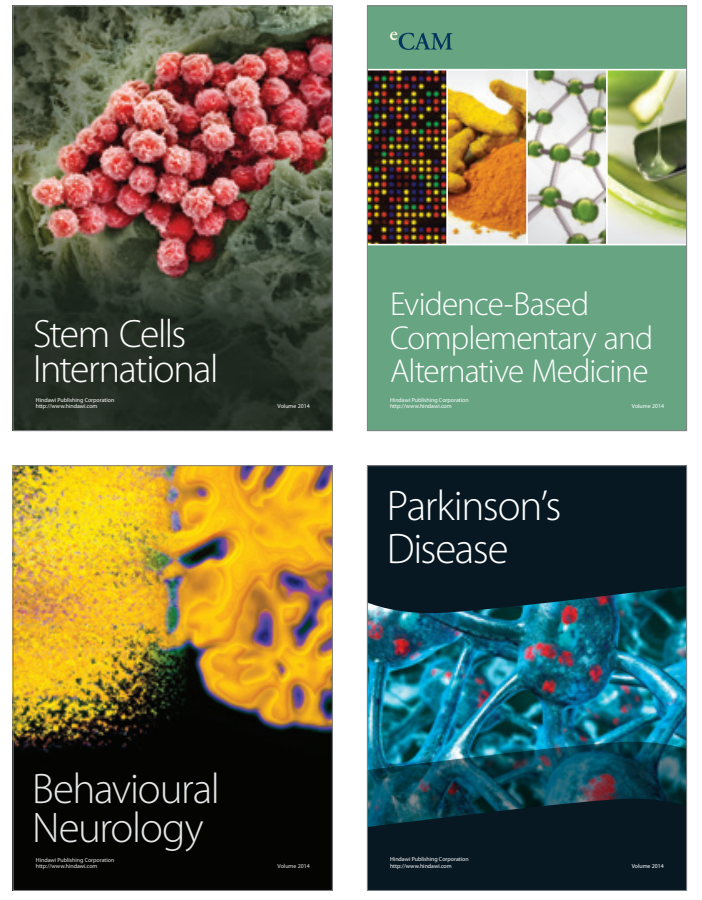
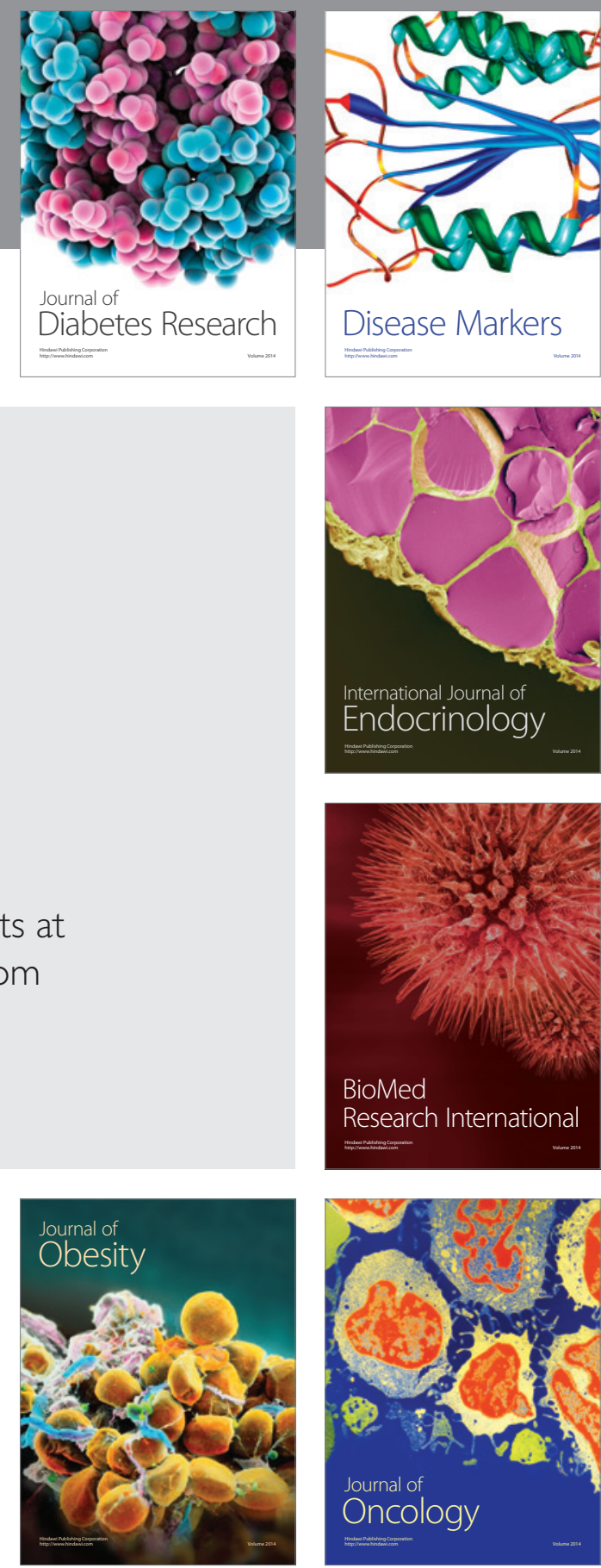

Disease Markers
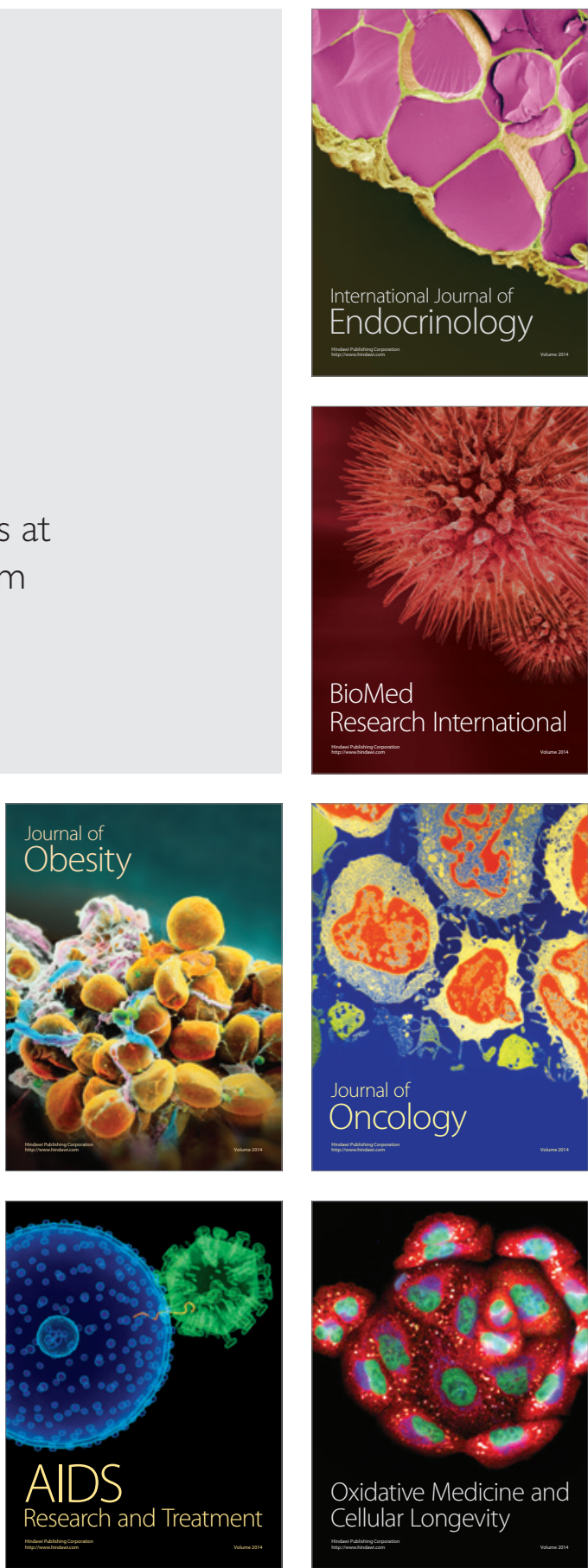